\title{
Extracellular Antifreeze Protein Significantly Enhances the Cryopreservation of Cell Monolayers
}

\author{
Ruben M. F. Tomás, ${ }^{\dagger}$ Trisha L. Bailey, ${ }^{\dagger}$ Muhammad Hasan, ${ }^{\dagger, \ddagger}$ and Matthew I. Gibson*, ${ }^{\dagger, \ddagger(0)}$ \\ ${ }^{\dagger}$ Department of Chemistry, University of Warwick, Gibbet Hill Road, Coventry CV4 7AL, United Kingdom \\ "Warwick Medical School, University of Warwick, Gibbet Hill Road, Coventry CV4 7AL, United Kingdom
}

\section{Supporting Information}

ABSTRACT: The cryopreservation of cells underpins many areas of biotechnology, healthcare, and fundamental science by enabling the banking and distribution of cells. Cryoprotectants are essential to prevent cold-induced damage. Here, we demonstrate that extracellular localization of antifreeze proteins can significantly enhance post-thaw recovery of mammalian cell monolayers cryopreserved using dimethyl sulfoxide, whereas they show less benefit in suspension cryopreservation. A type III antifreeze protein (AFPIII) was used as the macromolecular ice recrystallization inhibitor and its intra/extracellular locations were controlled by using Pep-1,

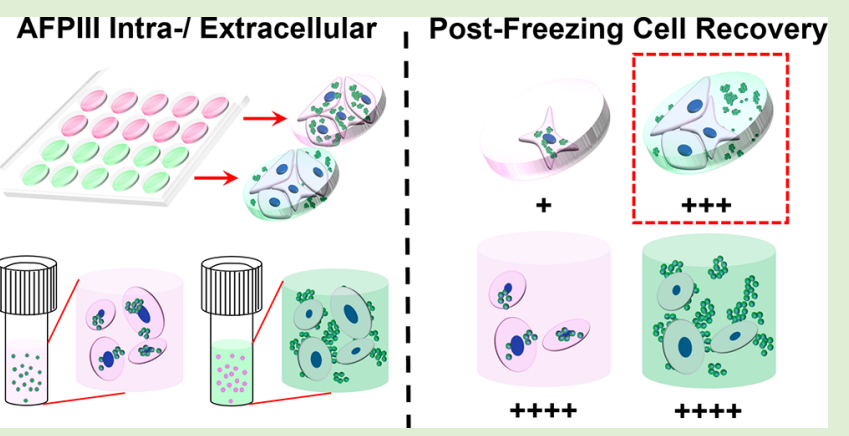
a cell-penetrating peptide. Flow cytometry and confocal microscopy confirmed successful delivery of AFPIII. The presence of extracellular AFPIII dramatically increased post-thaw recovery in a challenging $2-\mathrm{D}$ cell monolayer system using just $0.8 \mathrm{mg} \cdot \mathrm{mL}^{-1}$, from $25 \%$ to over $60 \%$, whereas intracellularly delivered AFPIII showed less benefit. Interestingly, the antifreeze protein was less effective when used in suspension cryopreservation of the same cells, suggesting that the cryopreservation format is also crucial. These observations show that, in the discovery of macromolecular cryoprotectants, intracellular delivery of ice recrystallization inhibitors may not be a significant requirement under "slow freezing" conditions, which will help guide the design of new biomaterials, in particular, for cell storage.

\section{INTRODUCTION}

Cell-based therapies are emerging as next-generation treatments for intractable and complex diseases (especially in oncology) which remain unresponsive to traditional "molecular" therapies. ${ }^{1}$ However, mammalian cell cryopreservation, for the long-term storage of cells and tissues, remains an essential part of the manufacturing process and has been identified as a potential bottleneck in the future development of complex cellular therapy products. ${ }^{2}$ Dimethyl sulfoxide (DMSO), a cell permeable cryoprotectant, remains the most widely used cryoprotective agent (CPA) for the cryopreservation of mammalian cells and tissues in cell suspension. ${ }^{3}$ During typical "slow freezing" approaches, DMSO enters cells and minimizes injury through reducing electrolyte concentration in residual unfrozen solution within and surrounding cells at any given temperature, thus reducing intracellular ice growth, cell shrinkage and osmotic shock during freezing. ${ }^{4,5}$ However, cell survival rates decrease due to DMSO cytotoxicity and inhibition of internal signaling. ${ }^{6,7}$ Furthermore, prolonged cryopreservation of stem cells approved for the treatment of various blood and immunological diseases and for large-scale banking and manufacturing can result in differentiation induced by histone alterations and DNA methylation, creating difficulties in the cryopreservation of material routinely used in clinical applications. ${ }^{8-11}$
Cryopreservation of cells in monolayer format is currently being investigated as a means to supply cells which can be readily used and do not experience extensive "phenotypic drift" due to time-consuming laboratory processes, such as inoculation and propagation, from frozen vials. Successful monolayer cryopreservation of cells would be revolutionary in minimizing batch-to-batch variation and for the development of 2- and 3-D cell models, tissue storage, viral diagnostics, and organ-on-a-chip applications. ${ }^{12-15}$ However, the current standard (DMSO) approaches used in suspension freezing are not translatable to monolayer freezing, with evidence suggesting that cells within a 2- and 3-D network (monolayers and spheroids/organoids) experience different modes of cryoinjury. ${ }^{16,17}$ Thus, development of novel cryoprotectants tailored toward the format of cryopreservation and to replace or reduce DMSO content is pivotal for the future development of cellbased therapies and diagnostics.

Naturally occurring CPAs, including trehalose, ${ }^{18}$ proline, ${ }^{17}$ sucrose, ${ }^{19}$ and antifreeze proteins (AFPs), ${ }^{20,21}$ as well as synthetic cryoprotectants, ${ }^{22-24}$ have been studied in the attempt to replace or improve DMSO cell suspension

Received: July 10, 2019

Revised: August 30, 2019

Published: September 9, 2019 
cryopreservation. In particular, AFPs (and their mimics) have received attention due to their potent ice recrystallization inhibition (IRI) properties and potential ability to stabilize membranes or modify ice nucleation. ${ }^{25-28}$ Ice recrystallization (growth) during thawing results in the formation of large ice crystals, at the expense of small crystals, causing cellular damage and is thus a major contributor to cell death. Although IRI active compounds have provided some benefits for cryopreserving erythrocytes, ${ }^{29-33}$ nucleated cell lines, ${ }^{34,35}$ and stem cells, ${ }^{36}$ complete removal of DMSO is rarely achieved. Furthermore, the influence of IRI active compounds on cells frozen in a monolayer format is poorly understood, as the mechanism of cryoinjury is different. Cell death during monolayer freezing is postulated to be caused by the propagation of intracellular ice between adjacent cells initiated by multiple mechanisms including surface-catalyzed nucleations (i.e., extracellular ice interacting with cell membrane forming a nucleation site for intracellular ice growth), ${ }^{37,38}$ cell-cell and cell-surface interaction with adjacent cells, ${ }^{39-41}$ or gap junctions within the membrane. ${ }^{16,42-44}$ Controlled slow freezing of suspension cells with DMSO (typically 5-10 wt \%) removes the risk of intracellular ice formation as the CPA enters the cells, causing more water to efflux, and reducing the likelihood of intracellular ice formation. ${ }^{45-47}$ However, in the extracellular media, ice formation and growth does occur, hence the potential benefits of ice recrystallization inhibitors. Conversely, monolayer freezing of cells using DMSO typically results in low post-thaw viability due to the intercellular contacts and limited diffusion between cells suggesting that monolayer freezing may benefit from intracellular IRI active macromolecules. ${ }^{17,48}$ Therefore, raising the question, "does the difference in ice growth during slow-freezing of cells in suspension and monolayer formats affect the benefits of intraversus extracellular localization of IRI active macromolecular cryoprotectant?" Bailey et al., ${ }^{48}$ Graham et al., ${ }^{17}$ and Matsumura et al. ${ }^{49}$ have previously shown that macromolecular cryoprotectants can have dramatic effects on cell monolayer cryopreservation. However, determining the ideal cellular location for macromolecular cryoprotectants would aid in the understanding and development of emerging cryoprotectants, especially since intracellular delivery of synthetic and natural macromolecules can be challenging. ${ }^{50}$

Considering the above, the aim of this study was to evaluate whether intra- or extracellular localization of ice recrystallization inhibition active macromolecules is advantageous to the cryopreservation of cells in suspension, monolayer, or both. Using a type III AFP (AFPIII) and an efficient cell-penetrating peptide, Pep-1, we delivered AFPIII inside or outside of cells. Extracellular AFPIII lead to a dramatic enhancement in the cryopreservation of a 2-D cell monolayer system, resulting in a 3 -fold increase in the total number of cells recovered compared to $10 \mathrm{wt} \%$ DMSO alone. In contrast, intracellular AFPIII only protected cells at a lower DMSO concentration, although with high variability, supporting the hypothesis that extracellular ice growth is a major cause of cell death. AFPIII failed to improve cell recoveries in suspension freezing regardless of localization. These results will help the rational design of more potent macromolecular cryopreservatives.

\section{EXPERIMENTAL SECTION}

Materials. Pep-1, Dulbecco phosphate buffered saline (DPBS), NucBlue Live Cell ReadyProbes Reagent, Alexa Fluor 488 C5Maleimide, ProLong Gold Antifade Alamar blue, Nalgene cryogenic tubes, $175 \mathrm{~cm}^{2}$ Nunc cell culture flasks, Fisherbrand Sterile Cell Strainers, BD Sphero Rainbow Calibration Particles (8 Peaks 3.0-3.4 $\mu \mathrm{m}$ ) and BD FACSFlow Sheath Fluid were purchased from Fisher Scientific (Loughborough, UK). Ham's F-12K (Kaighn's) Medium (F-12K) (Gibco, Paisley, UK) was supplemented with 10\% USA-origin fetal bovine serum (FBS) purchased from Sigma-Aldrich (Dorset, UK), 100 units $/ \mathrm{mL}$ penicillin, $100 \mu \mathrm{g} / \mathrm{mL}$ streptomycin, and $250 \mathrm{ng} / \mathrm{mL}$ amphotericin B (PSA) (HyClone, Cramlington, UK).

Physical and Analytical Methods. Ice Recrystallization Inhibition Assay (IRI). IRI was assessed using a Linkam Biological Cryostage BCS196 controlled with a T96-Linpad system controller equipped with a LNP95-Liquid nitrogen cooling pump (Linkam Scientific Instruments UK, Surrey, UK). Images were acquired using

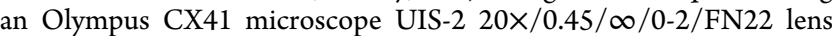
(Olympus Ltd., Southend on sea, UK) and a Canon EOS 500D SLR digital camera. Image processing and mean grain size measurements were completed using Image J $1.49 \mathrm{v}$.

Confocal Microscopy. A Zeiss LSM 880 inverted microscope equipped with $100 \times, 63 \times, 40 \times$, and $20 \times$ oil immersion objective lenses, three photomultiplier detectors (GaAsP, multialkali and BiG.2) and multichannel spectral imaging with an ultrasensitive GASP detector was used to acquire all confocal images. The UV and VIS Laser Modules allowed selection of six lasers with wavelengths of 633, 594, 561, 543, 514, 488, 458, 405, and $355 \mathrm{~nm}$. Zeiss ZEN (blue edition) 2.3 lite was utilized for image collection and processing. All other imaging was completed using an Olympus CX41 microscope equipped with a UIS-2 $20 \times / 0.45 / \infty / 0-2 /$ FN22 lens (Olympus Ltd., Southend on sea, U.K.) and a Canon EOS 500D SLR digital camera and processed using ImageJ $1.49 \mathrm{v}$.

Flow Cytometry. Flow cytometry was performed on a BD Influx cell sorter (BD Biosciences) equipped with 355-, 488-, 561-, and 642 $\mathrm{nm}$ lasers and detecting up to 24 parameters (21 fluorescence channels, two forward scatter channels and one side scatter). BD FACS Sortware software was used to operate the instrument. Sample analysis required the use of the $488 \mathrm{~nm}$ excitation laser and 530/30 $\mathrm{nm}$ filter. A $100 \mu \mathrm{m}$ nozzle was fitted, operating at a pressure of $20 \mathrm{psi}$ (sheath) and $21.5 \mathrm{psi}$ (sample). Stream and laser alignment was performed using BD Sphero Rainbow Calibration Particles (8 Peaks, 3.0-3.4 $\mu \mathrm{m}$ ), and all sample measurements consisted of a minimum of 100000 recorded events. Cell detachment was completed utilizing Accutase solution (Fisher Scientific) and passed through Fisherbrand Sterile Cell Strainers (Fisher Scientific) to ensure single cell analysis. Voltage settings applied ensured that nonfluorescent control cells appeared at low fluorescence emission intensities. FlowJo X 10.0.7r2 (Tree Star, Ashland, USA) was used for all statistical analysis and plotting of flow cytometry data.

Statistical Analysis. Data was analyzed with a one-way analysis of variance (ANOVA) on ranks followed by a comparison of experimental groups with the appropriate control group (Tukey's post hoc test). R (R Foundation for Statistical Computing, Vienna, Austria) was used for all statistical analysis.

AFPIII Cytotoxicity. A549 cells were plated in a 96-well plate (Corning Incorporated, Corning, NY) at a density of $2 \times 10^{5}$ cells. $\mathrm{mL}^{-1}$ with media supplemented with varying concentrations of AFPIII $\left(0-0.8 \mathrm{mg} \cdot \mathrm{mL}^{-1}\right)$ and incubated in a humidified atmosphere of $95 \%$ air and $5 \% \mathrm{CO}_{2}$ at $37{ }^{\circ} \mathrm{C}$ for $24 \mathrm{~h}$. Alamar blue reagent $(10 \%$ $\mathrm{v} / \mathrm{v}$ in cell media) was added to both AFPIII treated and untreated (control) cells. Absorbance measurements were obtained at 570 and $600 \mathrm{~nm}$ using a BioTek Synergy HT microplate reader to monitor the reduction of resazurin to resorufin by viable cells. Cells were incubated for $4 \mathrm{~h}$ at $37{ }^{\circ} \mathrm{C}$ and $5 \% \mathrm{CO}_{2}$ with readings obtained every $30 \mathrm{~min} / 1 \mathrm{~h}$. Total cell viability was reported relative to control cells grown solely in cell culture media alone.

Optimization of AFPIII Concentration for Vial Freezing. A549 cells were obtained from an adherent culture by detaching with $0.25 \%$ trypsin and $1 \mathrm{mM}$ EDTA in balanced salt solution, for $10 \mathrm{~min}$, in a humidified atmosphere of $5 \% \mathrm{CO}_{2}$ and $95 \%$ air, at $37{ }^{\circ} \mathrm{C}$. Viable cells were counted using a hemocytometer (Sigma-Aldrich), following treatment with $0.4 \%$ trypan blue solution (Sigma-Aldrich), and placed in cryogenic vials at a density of $200 \mathrm{k}$ cell. $\mathrm{mL}^{-1}$ (400k cells per vial) 
in F12-K media supplemented with $10 \%$ FBS, varying concentrations of AFPIII $\left(0-0.8 \mathrm{mg} \cdot \mathrm{mL}^{-1}\right)$, and DMSO (0-10 wt \%). Cryogenic vials were placed in a CoolCell LX freezing container (BioCision, LLC, Larkspur, CA), and frozen at $1{ }^{\circ} \mathrm{C} \cdot \mathrm{min}^{-1}$ to $-80^{\circ} \mathrm{C}$. Vials were subsequently stored in the vapor phase of a liquid nitrogen dewar $\left(-196^{\circ} \mathrm{C}\right)$ for $24 \mathrm{~h}$. Cells were rapidly thawed at $37^{\circ} \mathrm{C}$, transferred to warm complete FK-12 media $(9 \mathrm{~mL})$, and centrifuged at $2 g$ for $5 \mathrm{~min}$. The cell pellet was resuspended in complete media, transferred into a 24-well plates (Corning Incorporated, Corning, NY), and incubated in a humidified atmosphere of $5 \% \mathrm{CO}_{2}$ and $95 \%$ air at $37^{\circ} \mathrm{C}$ for $24 \mathrm{~h}$. Finally, cell viability was assessed by counting the number of viable cells (i.e., with intact membrane), as described above, and dividing by the total number of cells initially frozen. Four biological repeats were conducted.

Optimization of AFPIII Transfection Using Pep-1. A549 cells were plated in a 24-well plate at a density of $800 \mathrm{k} \mathrm{cell} \cdot \mathrm{mL}^{-1}(400 \mathrm{k}$ cell per well), to achieve a confluent monolayer, and left to attach for $24 \mathrm{~h}$ in a humidified atmosphere of $5 \% \mathrm{CO}_{2}$ and $95 \%$ air at $37{ }^{\circ} \mathrm{C}$. Pep- 1 ( $\left.1 \mathrm{mg} \cdot \mathrm{mL}^{-1}\right)$, dissolved in ultrapure $\mathrm{H}_{2} \mathrm{O}$, and AFPIII-Alexa Fluor $488\left(0.25-2 \mathrm{mg} \cdot \mathrm{mL}^{-1}\right)$, dissolved in PBS, were mixed in a $1: 1$ ratio and incubated at room temperature for $30 \mathrm{~min}$. Cells were incubated with the AFPIII-Alexa Fluor 488/Pep-1 mixtures $(100 \mu \mathrm{L})$ for $30 \mathrm{~min}$ in a humidified atmosphere and for a further $1 \mathrm{~h}$ after adding F12-K media without an additional supplement $(100 \mu \mathrm{L})$. Complete F12-K media $(100 \mu \mathrm{L})$ was added, and cells were further incubated for $1 \mathrm{~h}$. Cells were imaged using the Olympus CX41 microscope described above (Supporting Information). The procedure was repeated with the optimized final concentration of AFPIII-Alexa Fluor 488 (0.8 mg. $\left.\mathrm{mL}^{-1}\right)$ and Pep-1 $\left(0.5 \mathrm{mg} \cdot \mathrm{mL}^{-1}\right)$. Fluorescence quantification was achieved using flow cytometry, and confocal images were obtained following fixation with $4 \%$ paraformaldehyde $(15 \mathrm{~min})$ and staining with NucBlue Live Cell ReadyProbes. Cells untreated and treated solely with AFPIII-Alexa Fluor $488\left(0.8 \mathrm{mg} \cdot \mathrm{mL}^{-1}\right)$ or Pep-1 $(0.5 \mathrm{mg}$. $\left.\mathrm{mL}^{-1}\right)$ in PBS:water (1:1) were also analyzed to determine nonspecific binding, Pep-1 fluorescence, and cell autofluorescence.

Cell Suspension Freezing. Suspension freezing of A549 cells was conducted under five conditions: (1) in DMSO solutions (0-10 wt $\%) ;(2)$ in solutions containing AFPIII $\left(0.05 \mathrm{mg} \cdot \mathrm{mL}^{-1}\right)$ and DMSO (0-10 wt \%); (3) incubated with Pep-1 $\left(0.5 \mathrm{mg} \cdot \mathrm{mL}^{-1}\right)$ and subsequently frozen in DMSO solutions $(0-10 \mathrm{wt} \%)$; (4) transfected with AFPIII $\left(0.8 \mathrm{mg} \cdot \mathrm{mL}^{-1}\right)$ using Pep-1 $\left(0.5 \mathrm{mg} \cdot \mathrm{mL}^{-1}\right)$ and frozen in DMSO solutions (0-10 wt \%); (5) transfected with AFPIII (0.8 mg. $\left.\mathrm{mL}^{-1}\right)$ using Pep-1 $\left(0.5 \mathrm{mg} \cdot \mathrm{mL}^{-1}\right)$ and frozen in solutions containing DMSO (0-10 wt \%) and AFPIII $\left(0.05 \mathrm{mg} \cdot \mathrm{mL}^{-1}\right)$. For conditions (1) and (2), A549 cells were obtained from an adherent culture and placed in cryogenic vials at a density of $400 \mathrm{k} \mathrm{cell} \cdot \mathrm{mL}^{-1}(400 \mathrm{k}$ cells per vial) in unsupplemented F12-K media. F12-K media supplemented with $20 \%$ FBS and DMSO (0-20 wt \%) (1) or both DMSO (0-20 wt \%) and AFPIII $\left(0.1 \mathrm{mg} \cdot \mathrm{mL}^{-1}\right)(2)$ was added to the cryogenic vial at a 1:1 ratio to achieve the desired final concentration and cell density. For treatments (4) and (5), AFPIII transfection into A549 cells using Pep-1 was completed as described above with the optimized concentrations. Cells were also incubated with Pep-1 (0.5 $\left.\mathrm{mg} \cdot \mathrm{mL}^{-1}\right)$ dissolved in PBS: $\mathrm{H}_{2} \mathrm{O}(1: 1)$, following the same protocol for transfection but without AFPIII, to determine extent of Pep-1 influence on cell recovery after freeze-thawing (3). Following completion of each treatment, cell detachment was achieved using trypsin and placed in cryogenic vials at a density of $400 \mathrm{k} \mathrm{cell} \cdot \mathrm{mL}^{-1}$ (400k cells per vial) in unsupplemented F12-K media. F12-K media supplemented with $20 \% \mathrm{FBS}$ and either DMSO (0-20 wt \%) (3 and 4) or DMSO (0-20 wt \%) and AFPIII $\left(0.1 \mathrm{mg} \cdot \mathrm{mL}^{-1}\right)$ (5) was subsequently added to the cryogenic vial at a $1: 1$ ratio to achieve the desired final concentration and cell density. Cryogenic vials were placed in a CoolCell LX freezing container and frozen as described previously during the optimization of AFPIII concentration for vial freezing. Viable cells were counted using a hemocytometer, following treatment with $0.4 \%$ trypan blue solution, and reported relative to the total number of cells initially frozen. At least 4 biological repeats were conducted.
Cell Monolayer Freezing. Monolayer freezing of A549 cells was conducted using four treatments: (1) in DMSO solutions (0-10 wt $\%) ;(2)$ in DMSO solutions (0-10 wt \%) following incubation in AFPIII $\left(0.8 \mathrm{mg} \cdot \mathrm{mL}^{-1}\right)$; (3) incubated with Pep-1 $\left(0.5 \mathrm{mg} \cdot \mathrm{mL}^{-1}\right)$ and subsequently frozen in DMSO solutions $(0-10$ wt \%); and (4) AFPIII $\left(0.8 \mathrm{mg} \cdot \mathrm{mL}^{-1}\right)$ transfection using Pep-1 $\left(0.5 \mathrm{mg} \cdot \mathrm{mL}^{-1}\right)$ and cryopreserved in DMSO solutions (0-10 wt \%). A549 cells were plated in a 24 -well plate at a density of $800 \mathrm{k} \mathrm{cell} \cdot \mathrm{mL}^{-1}(400 \mathrm{k}$ cells per well), to achieve a confluent monolayer, and left to attach for $24 \mathrm{~h}$ in a humidified atmosphere of $5 \% \mathrm{CO}_{2}$ and $95 \%$ air at $37{ }^{\circ} \mathrm{C}$. The following solutions were prepared in PBS: $\mathrm{H}_{2} \mathrm{O}(1: 1)$ and added (100 $\mu \mathrm{L})$ to the corresponding treatments: (1) PBS: $\mathrm{H}_{2} \mathrm{O}$ solution alone; (2) AFPIII $\left(0.8 \mathrm{mg} \cdot \mathrm{mL}^{-1}\right)$; (3) Pep-1 $\left(0.5 \mathrm{mg} \cdot \mathrm{mL}^{-1}\right)$; (4) AFPIII $\left(0.8 \mathrm{mg} \cdot \mathrm{mL}^{-1}\right)$ and Pep-1 $\left(0.5 \mathrm{mg} \cdot \mathrm{mL}^{-1}\right)$ after leaving for $30 \mathrm{~min}$ to complex. A549 cells were incubated in these solutions for $30 \mathrm{~min}$ in a humidified environment and for a further $1 \mathrm{~h}$ after adding F12-K media without an additional supplement $(100 \mu \mathrm{L})$. Complete F12-K media $(100 \mu \mathrm{L})$ was added, and cells were further incubated for $1 \mathrm{~h}$. All solutions were removed and, for every condition, cells were incubated with DMSO (0-10 wt \%) for $10 \mathrm{~min}$. After $10 \mathrm{~min}$, DMSO solutions were removed and the plate was placed inside a CoolCell MP plate (BioCision), transferred to a $-80^{\circ} \mathrm{C}$ freezer, and frozen at a rate of $1{ }^{\circ} \mathrm{C} \cdot \mathrm{min}^{-1}$. After $24 \mathrm{~h}$ at $-80{ }^{\circ} \mathrm{C}$, cells were rapidly thawed using complete $\mathrm{F} 12-\mathrm{K}$ media $(500 \mu \mathrm{L})$ and placed in a humidified atmosphere of $5 \% \mathrm{CO}_{2}$ and $95 \%$ air at $37{ }^{\circ} \mathrm{C}$ for $24 \mathrm{~h}$. Viable cells were counted using a hemocytometer, following treatment with $0.4 \%$ trypan blue solution, and reported relative to the total number of cells initially frozen. Three biological repeats were conducted.

\section{RESULTS AND DISCUSSION}

To evaluate the intracellular versus extracellular impact of macromolecular cryoprotectants, a type III antifreeze protein from ocean pout (AFPIII) was selected. The rationale for using an antifreeze protein, as opposed to polymeric cryoprotectants, was their high IRI activity (capable of inhibiting all ice growth well below $\left.0.1 \mathrm{mg} \cdot \mathrm{mL}^{-1}\right)^{23}$ and the ability to use established methods (see below) to enable cellular delivery of proteins. Recombinant AFPIII was expressed in Escherichia coli (E. coli) and purified according to previously published methods (Supporting Information). ${ }^{51}$ Site-directed mutagenesis of the terminal Ala present within the AFPIII encoding plasmid was used to produce a mutant cysteine variant of AFPIII (AFPCys), enabling site-specific conjugation to Alexa Fluor 488 Maleimide (AFPIII-Alexa Fluor 488) for fluorescence-based quantification and imaging (Supporting Information).

A549 (adenocarcinomic human alveolar basal epithelial) cells were chosen as a model cell line for cryopreservation studies. To assess the role of intra- versus extracellular AFPIII during mammalian cell cryopreservation, translocation of AFPIII into the cells was essential. The cell-penetrating peptide Pep-1 was selected for this purpose, as it is known to be a broadly applicable cell-uptake enhancing peptide via a nonendocytic mechanism. ${ }^{52-56}$ Due to the extensive literature available on Pep-1 mediated translocation of protein cargoes, the mechanism of complexation with AFPIII was not studied here. There is evidence to suggest that Pep-1 forms a complex with protein cargos through hydrophobic and electrostatic interactions and adopts a helical structure upon interaction with the plasma membrane lipids, allowing insertion into the lipid bilayer. The complex is then released into the cytoplasm with partial "decaging" of the cargo. However, the exact mechanism of complexation was irrelevant to the cryopreservation of mammalian cells and the overall aim of this study.

To determine the minimum concentration of AFPIII required for cellular delivery, a range of AFPIII-Alexa Fluor 
488 concentrations $\left(0.125-1 \mathrm{mg} \cdot \mathrm{mL}^{-1}\right)$ were incubated with a fixed concentration of Pep-1 $\left(0.5 \mathrm{mg} \cdot \mathrm{mL}^{-1}\right)$ for $30 \mathrm{~min}$, to form protein/peptide cargos, and subsequently applied to A549 monolayers $(2.5 \mathrm{~h})$. AFPIII-Alexa Fluor 488 uptake was monitored using fluorescence microscopy (Supporting Information, Figure S1). Internalization of AFPIII was observed at concentrations of 0.5 and $1 \mathrm{mg} \cdot \mathrm{mL}^{-1}$, so an intermediate concentration of $0.8 \mathrm{mg} \cdot \mathrm{mL}^{-1}$ was selected for the intracellular delivery of AFPIII using Pep-1 in all subsequent experiments, with a 1:1.65 molar ratio of AFPIII to Pep-1. Higher Pep-1/ cargo ratios are often used (20:1 or 10:1); however, previous reports suggest that such high concentrations can result in the formation of aggregates that are poorly taken into the cell and accumulate on the cell surface or endosomes. ${ }^{53,55}$ Therefore, to minimize these issues, while still ensuring AFPIII internalization, a 1:1.65 molar ratio was optimal. Further (quantitative) uptake studies were also explored (below). With a working range established, the cytotoxicity of AFPIII toward A549 cells was evaluated to ensure that any cryopreservative effects, either positive or negative, were not skewed by intrinsic cytotoxicity. A549 cells were incubated with AFPIII (0-0.8 $\mathrm{mg} \cdot \mathrm{mL}^{-1}$ ) for $24 \mathrm{~h}$ and cell viability was assessed using the resazurin reduction assay to determine any changes to cell metabolic activity. Over $88 \%$ cell viability was obtained, even at the highest concentrations, demonstrating minimal effect to cellular metabolic activity (Figure 1) and an advantage over cytotoxic CPAs.

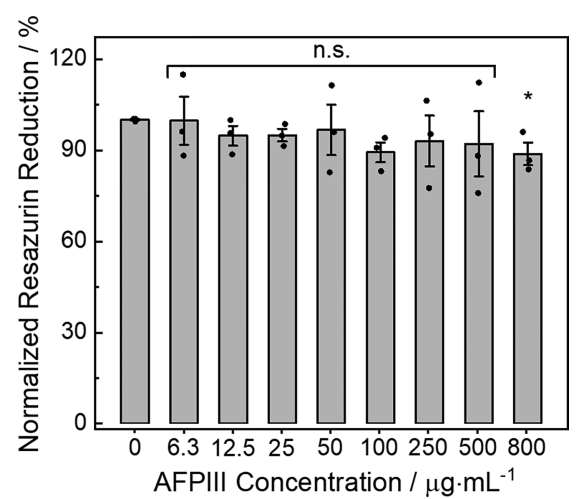

Figure 1. AFPIII cytotoxicity against A549 cells. Cells were incubated with AFPIII $\left(0-0.8 \mathrm{mg} \cdot \mathrm{mL}^{-1}\right.$ for $\left.24 \mathrm{~h}\right)$ and cellular metabolic activity was assessed using the resazurin reduction assay. The data is represented by the mean value $\pm \operatorname{SEM}(n=3$, n.s. $p>0.05, * p \leq 0.05$ compared to cells untreated with AFPIII).

To further demonstrate the extent of intracellular incorporation of AFPIII with Pep-1, confocal images were obtained using the optimized molar ratio of AFPIII-Alexa Fluor 488 and Pep-1 (1:1.65) shown in Figure 2A. The peptide/protein cargo was allowed to complex for $30 \mathrm{~min}$ and then applied to confluent monolayers of A549 cells for $2.5 \mathrm{~h}$, mimicking the suspension and monolayer pretreatment conditions used later in the freezing protocol. Confocal images clearly indicated enhanced uptake (green channel) when both Pep-1 (0.5 mg. $\left.\mathrm{mL}^{-1}\right)$ and AFPIII-Alexa Fluor $488\left(0.8 \mathrm{mg} \cdot \mathrm{mL}^{-1}\right)$ were present, compared to AFPIII-Alexa Fluor 488 alone, suggesting that AFPIII internalization is minimal without the use of Pep-1. These results further validate our use of AFPIII for investigating intracellular versus extracellular impact of macromolecular cryoprotectants on mammalian cell cryopreservation. This was further corroborated using flow cytometry
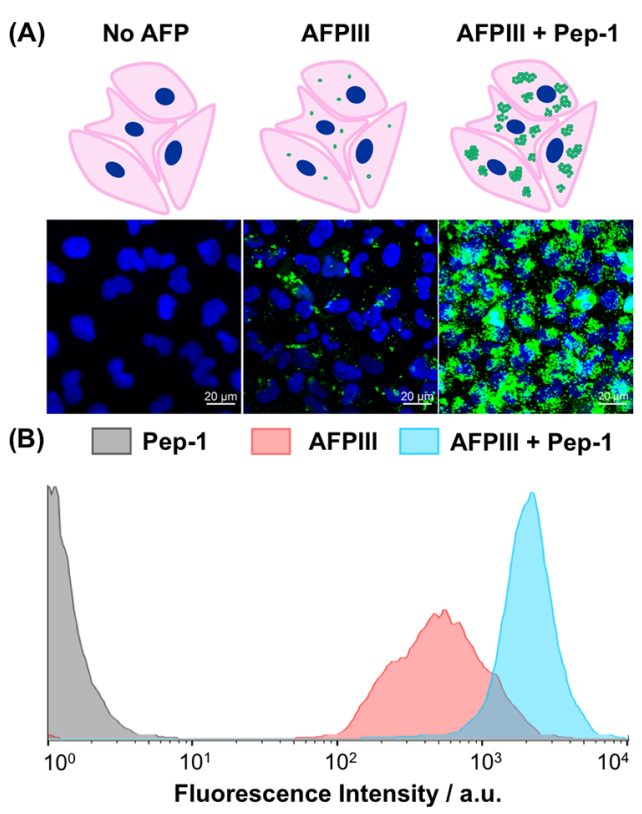

Figure 2. AFPIII translocation into A549 cells using Pep-1. (A) Confocal microscopy (merge blue and green channels) and (B) flow cytometry analysis of AFPIII-AlexaFluor488 $\left(0.8 \mathrm{mg} \cdot \mathrm{mL}^{-1}\right)$ delivery using Pep-1 $\left(0.5 \mathrm{mg} \cdot \mathrm{mL}^{-1}\right)$. Scale bar $=20 \mu \mathrm{m}$. Blue = DAPI. Green $=$ AFPIII-Alexa Fluor 488.

analysis, with Pep-1 leading to approximately 5 times more uptake of AFPIII (Figure 2B). Confocal z-stack images revealed fluorescence localized throughout the cytoplasm, which was essential when assessing the importance of intraversus extracellular AFPIII (Supporting Information, Figures S2-S5). In addition, there were no visible changes to A549 cell morphology or membrane integrity when transfecting AFPIII with Pep-1.

Following optimization of intracellular AFPIII delivery, determining the optimum concentration of extracellular AFPIII (in solution) was essential to maximize post-thaw cell recovery. A549 cells were cryopreserved in a suspension containing DMSO (0-10 wt \%) and AFPIII $\left(0-0.8 \mathrm{mg} \cdot \mathrm{mL}^{-1}\right)$. Cells were allowed to recover for $24 \mathrm{~h}$ post-thaw, before determining cell recovery (Figure 3). [Note: the $24 \mathrm{~h}$ incubation period post-thaw is vital to avoid false positive results associated with short post-thaw times, where any additive can give the impression of cryoprotection if apoptotic processes are not allowed time to complete]. ${ }^{57}$ Cell recovery was determined using the trypan blue exclusion assay for cell viability and the total number of viable cells were compared to an unfrozen control. This method provides total cell recovery, as damaged cells are not counted, compared to methods that only measure the viability of the recovered cells, which typically ignores highly damaged cells and can overestimate cell recovery values by not taking into account the number of cells recovered postthaw (e.g., 50\% of cells recovered, however $100 \%$ are viable). A549 cells were also frozen in equivalent DMSO solutions (0$10 \mathrm{wt} \%)$ to provide a comparable standard freezing approach for the assessment of post-thaw cell recovery. Unsurprisingly, A549 cells frozen in 10 wt \% DMSO alone outperformed lower concentrations for this cell line, with an average post-thaw recovery of $67 \%$. These results are consistent with those reported by Bailey et al. ${ }^{48}$ Addition of AFPIII at $0.8 \mathrm{mg} \cdot \mathrm{mL}^{-1}$ to the media resulted in a dramatic loss in post-thaw cells at all DMSO concentrations. The decrease in cell viability witnessed 


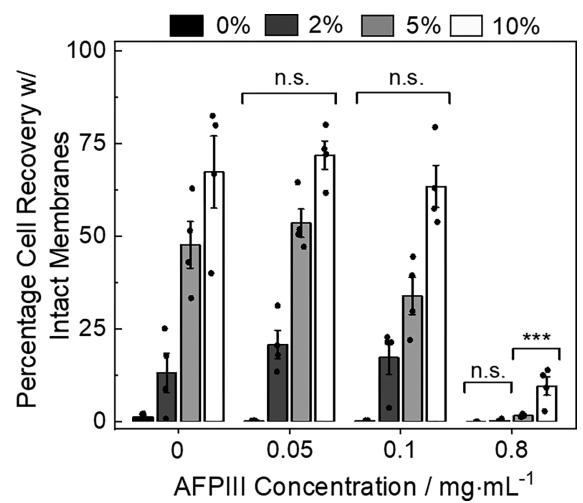

Figure 3. Post-thaw cell viability following suspension freezing of A549 cells with AFPIII. A549 cells were cryopreserved in DMSO (0$10 \mathrm{wt} \%)$ and AFP $\left(0-0.8 \mathrm{mg} \cdot \mathrm{mL}^{-1}\right)$ for $24 \mathrm{~h}$ at $-80^{\circ} \mathrm{C}$. Recovered cells were counted by trypan blue exclusion assay relative to unfrozen controls. The data represents the mean value $\pm \operatorname{SEM}(n=4$, n.s. $p>$ $0.05, * * * p \leq 0.001$ compared to cell recovery at equivalent DMSO concentrations with no AFPIII).

at high AFPIII concentrations is consistent with previous work, where AFPIII's ice shaping capabilities result in the formation of destructive "needle-shaped" ice which can pierce cell membranes and vital internal structures during freezing. $^{20,33,58,59}$ Lower concentrations of AFPIII (0.1 and 0.05 $\mathrm{mg} \cdot \mathrm{mL}^{-1}$ ) lead to almost identical results to DMSO alone, with slight differences in cell recovery being statistically insignificant. During freezing, AFPIII adsorbs onto prismatic and bipyramidal ice faces without attaching to basal faces, allowing the development of bipyramidal ice crystals, which "burst" along the $c$-axis when the freezing point is reached forming "needle-shaped" ice crystals. Vorontsov et al. ${ }^{60}$ and Ishiguro and Rubinsky ${ }^{61}$ revealed that lower AFPIII concentrations form dendritic ice growth whereas higher concentrations result in the development of cell damaging spicular ice crystals. Thus, to avoid cell injury and maximize recoveries post-thaw, $0.05 \mathrm{mg} \cdot \mathrm{mL}^{-1}$ AFPIII was used as the external CPA concentration for further suspension cryopreservation studies.

As a final control, it was also necessary to confirm if the presence of Pep-1 had any impact on the ice recrystallization inhibition (IRI) activity of AFPIII, a crucial cryoprotective function of this protein, as any changes could give rise to false positive cryopreservation results. The "splat" assay was used to assess changes in IRI activity, whereby small ice crystals are nucleated in a wafer and annealed at $-8{ }^{\circ} \mathrm{C}$ for $30 \mathrm{~min} .{ }^{62,63}$ Following this, the mean grain size of the crystals was determined, and reported relative to a negative control (PBS). AFPIII demonstrated potent IRI activity, as shown in Figure 4, inhibiting all ice growth at concentrations below $0.01 \mathrm{mg}$. $\mathrm{mL}^{-1}$. This value is consistent with previous reports, demonstrating superior and consistent IRI capabilities compared to other cryopreservants. ${ }^{51}$ This recrystallization inhibition effect is maintained, if not slightly enhanced, in the presence of $0.5 \mathrm{mg} \cdot \mathrm{mL}^{-1}$ Pep- 1 , which is the working concentration of the peptide used in this study. Pep-1 alone was found to present negligible IRI activity, eliminating the possibility of results being enhanced or depleted by Pep-1 interactions. These results indicate that Pep-1 translocation of AFPIII was an ideal choice to ensure AFPIII's IRI activity was retained, allowing a direct comparison between the benefits of localizing IRI active macromolecules intra- versus extracellularly.
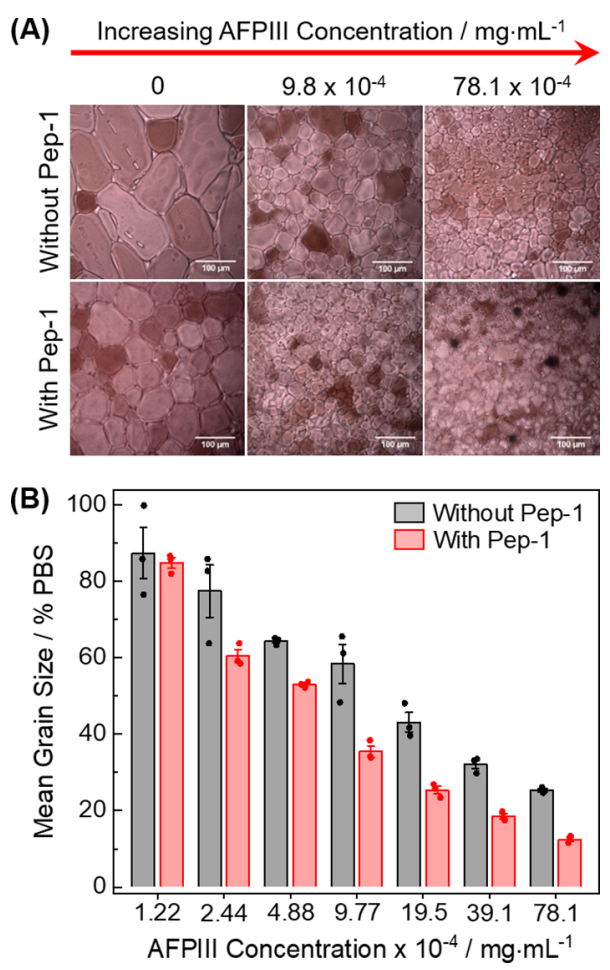

Figure 4. Ice recrystallization inhibition of AFPIII with or without Pep-1. (A) Example cryo-micrographs of ice wafers after $30 \mathrm{~min}$ of annealing with AFPIII in the presence and absence of Pep-1 $(0.5 \mathrm{mg}$. $\left.\mathrm{mL}^{-1}\right)$. (B) Dose-dependence of ice recrystallization inhibition activity. Mean grain size was calculated relative to PBS (negative) control. The data represents the mean value $\pm \operatorname{SEM}(n=3)$.

Guided by the above data, the impact of intra/extracellular AFPIII on cryopreservation was evaluated. A549 cells were cryopreserved in suspension using 0-10 wt \% DMSO alone, or with AFPIII either complexed with Pep-1 or AFPIII alone. Cell recovery was determined $24 \mathrm{~h}$ post-thaw using the trypan blue exclusion assay. As can be seen in Figure 5, Pep-1 alone lead to a small decrease in post-thaw recovery in $10 \mathrm{wt} \%$ DMSO. A resazurin reduction assay was completed of Pep-1, Figure S7, revealing that uncomplexed Pep-1 at the concentrations used to complex with AFPIII, results in a significant $(P \leq 0.05)$ decrease in cell viability. Therefore, this slight decrease in cell recovery can be attributed to uncomplexed Pep-1 cytotoxicity. The presence of AFPIII intracellularly, extracellularly, or both, surprisingly lead to minimal changes in post-thaw cell recovery. A small decrease in cell recovery was noted in the presence of intracellular AFPIII at all DMSO concentrations, but this was found to be statistically insignificant. There have been previous reports of intracellular ice recrystallization inhibitors enhancing the cryopreservation of red blood cells using glycerol (red blood cells are not stored in DMSO); ${ }^{32}$ however, in that particular case, the conditions (low glycerol and transient cooling/warming) were deliberately chosen to promote intracellular ice growth. Here, by using slow freezing rates lethal intracellular ice growth should be prevented/reduced however the formation of extracellular ice growth remains an issue. Extracellular AFPIII only increased post-thaw cell viability by approximately $6 \%$ at equal DMSO concentrations between 2 and 10 wt \%. This data supports the hypothesis that, for optimized suspension cryopreservation systems (such as this one), inhibiting ice recrystallization does not significantly increase viability. The highest percentage increase occurred 

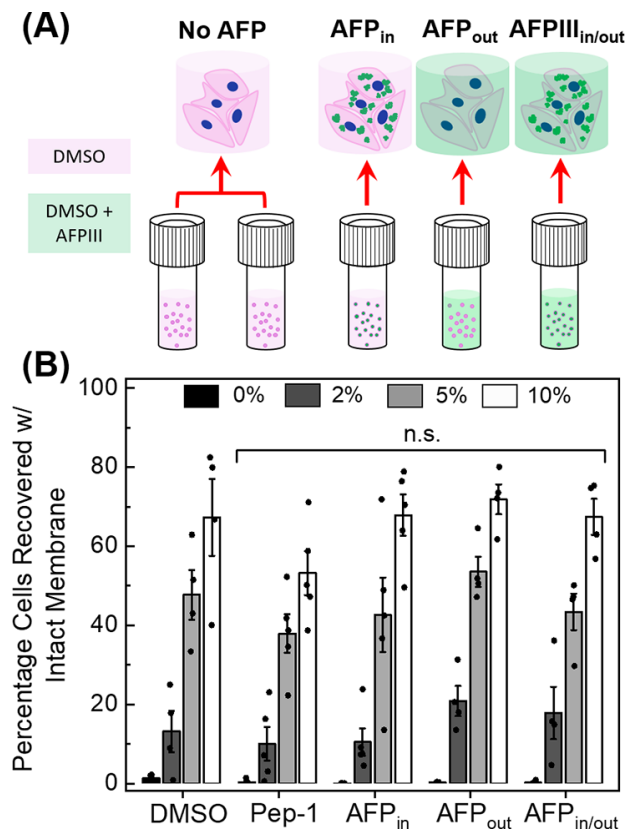

Figure 5. Suspension cryopreservation of A549 cells. (A) Cells were frozen with internalized AFPIII $\left(0.8 \mathrm{mg} \cdot \mathrm{mL}^{-1}\right)$ translocated using Pep-1 $\left(0.5 \mathrm{mg} \cdot \mathrm{mL}^{-1}\right)\left(\mathrm{AFP}_{\text {in }}\right)$, AFPIII within the CPA (0.05 mg. $\left.\mathrm{mL}^{-1}\right)\left(\mathrm{AFP}_{\text {out }}\right)$ or both $\left(\mathrm{AFP}_{\text {in/out }}\right)$ and with varying DMSO concentrations (0-10 wt \%). Control cells were also cryopreserved in DMSO and Pep-1 for comparison. (B) Post-thaw cell recovery was calculated by trypan blue exclusion assay relative to unfrozen controls. The data represents the mean value $\pm \operatorname{SEM}(n \geq 4$, n.s. $p>0.05$ compared to cell recovery at equivalent DMSO concentrations with no AFPIII).

when 2 wt \% DMSO was used, with an increase from $13.1 \%$ to $21.0 \%$, a nonideal concentration for these cells. Unfortunately, percentage recovery values still remained low despite the presence of AFPIII as the lack of DMSO most likely introduced additional mechanisms of cell death which IRI active compounds do not account for including exposure to excessively high concentrations of electrolytes ("solute effect") causing irreparable damage to the cell membrane and osmotic volume excursions exceeding cell tolerance. ${ }^{4}$ However, extracellular AFPIII (or other IRIs) appeared to show application in the cryopreservation of cells requiring low DMSO storage, due to susceptibility to cytotoxicity or induced differentiation, and where ice recrystallization is a more significant contributor to cell death.

The above results suggested that the intra/extracellular localization of AFPIII was not sufficient for enhancing mammalian cell cryopreservation in suspension freezing. While this is the most standard cell cryopreservation format, there is a real need to develop technologies and methods for 2and 3-D cell models, for tissue storage and organ-on-a-chip applications. ${ }^{13-15}$ The monolayer freezing protocol is illustrated in Figure 6A. A549 monolayers were frozen in DMSO alone, or with AFPIII $\left(0.8 \mathrm{mg} \cdot \mathrm{mL}^{-1}\right)$, AFPIII $\left(0.8 \mathrm{mg} \cdot \mathrm{mL}^{-1}\right)$ plus Pep-1 $\left.\left(0.5 \mathrm{mg} \cdot \mathrm{mL}^{-1}\right)\right)$, or Pep-1 alone $\left(0.5 \mathrm{mg} \cdot \mathrm{mL}^{-1}\right)$. Cells were incubated with these cryoprotectants for $2.5 \mathrm{~h}$, except for DMSO alone where incubation with media was completed, followed by incubation with DMSO (0-10 wt \%) concentrations for $10 \mathrm{~min}$. This procedure allowed time for intracellular translocation of Pep-1 with AFPIII and maintained the same AFPIII, Pep-1, and DMSO exposure times
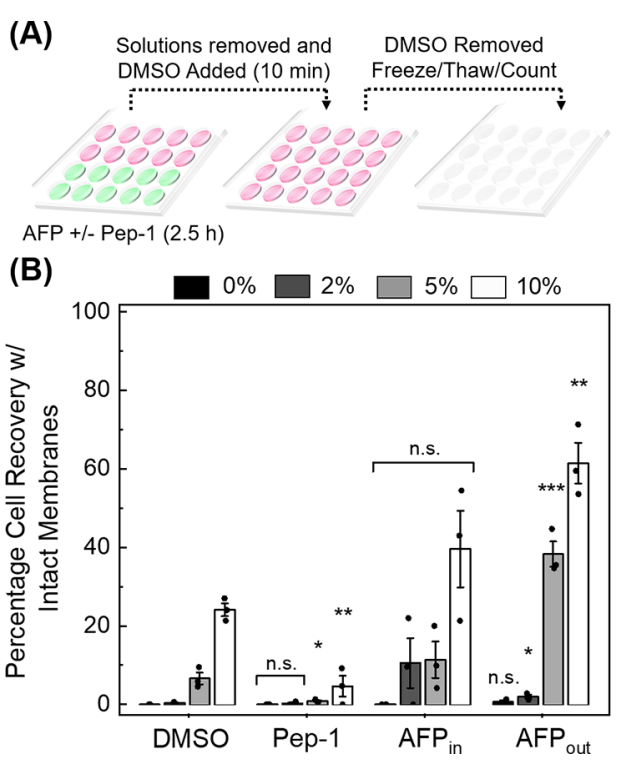

Figure 6. A549 cell monolayer cryopreservation. (A) Cells were incubated with either media (DMSO), Pep-1 $\left(0.5 \mathrm{mg} \cdot \mathrm{mL}^{-1}\right)$, AFPIII $\left(0.8 \mathrm{mg} \cdot \mathrm{mL}^{-1}\right)$ translocated using Pep-1 $\left(0.5 \mathrm{mg} \cdot \mathrm{mL}^{-1}\right)\left(\mathrm{AFP}_{\text {in }}\right)$ or AFPIII within the solution $\left(0.8 \mathrm{mg} \cdot \mathrm{mL}^{-1}\right)\left(\mathrm{AFP}_{\text {out }}\right)$ for $2.5 \mathrm{~h}$. Following removal of solutions, cells were incubated with DMSO concentrations $(0-10 \mathrm{wt} \%)$ and frozen at $1{ }^{\circ} \mathrm{C} \cdot \mathrm{min}^{-1}$ to $-80^{\circ} \mathrm{C}$. (B) Cell recovery was determined by trypan blue exclusion assay relative to unfrozen controls. The data represents the mean value \pm SEM $(n=$ 3 ; n.s. $p>0.05, * p \leq 0.05, * * p \leq 0.01$ and $* * * p \leq 0.001$ compared to percentage cell recovery values at equivalent DMSO concentrations with no AFPIII).

under all relevant conditions. Excess solution was removed, and cell monolayers were frozen at a controlled freezing rate of $1{ }^{\circ} \mathrm{C} \cdot \mathrm{min}^{-1}$ to $-80{ }^{\circ} \mathrm{C}$ using a CoolCell MP plate. Confocal images revealed that incubation with DMSO did not affect the cells' ability to retain transfected AFPIII (Supporting Information, Figures S2-S5).

As expected, cryopreservation in DMSO alone lead to limited cell recovery, with $25 \%$ cell recovery achieved using 10 wt \% DMSO, substantially lower compared to suspension cell cryopreservation due to the intercellular contacts and limited diffusion between cells, minimizing DMSO's capabilities of reducing intracellular ice growth. Lower DMSO concentrations provided less recovery. Surprisingly, Pep-1 alone resulted in a significant decrease in cell recovery. As previously discussed, uncomplexed Pep-1 is cytotoxic at the concentrations used; however, resazurin reduction was still $80 \%$ relative to control cells, Figure S7. Thus, cytotoxicity cannot be the only contributing factor. Uncomplexed Pep-1 may be interacting with membrane proteins and thus weakening membrane integrity and making it more susceptible to ice damage. Intracellular AFPIII lead to an increase in cell recovery at all DMSO concentrations, however with high variability. Compared to all other treatments, intracellular AFPIII provided the highest increase in cell recoveries, from $0.3 \%$ to $10.5 \%$, when 2 wt \% DMSO (i.e., lower DMSO concentrations) was used. Poisson et al. ${ }^{64}$ demonstrated that cell permeable small molecules, aryl glycosides, possessing IRI activity can reduce intracellular ice recrystallization content and increase post-thaw cell viability of red blood cells and human umbilical vein endothelial cells frozen with low glycerol. DMSO and glycerol both provide cryoprotection using the same mechanism of action, by reducing the 
concentration of either CPAs the risk of intracellular ice growth increases. This suggests that intracellular AFPIII is likely reducing intracellular ice recrystallization, thus reducing the chances of larger crystals forming during freeze-thaw and cell death. Intracellular ice is particularly problematic in monolayer freezing due to intracellular ice propagation from cell-cell and cell-surface interaction with adjacent cells, or gap junctions within the membrane. ${ }^{41,43,44}$ Therefore, intracellular localization of IRI active compounds, such as AFPIII, may find use in situations where lower DMSO concentrations are beneficial.

Extracellular AFPIII gave rise to significant increases in postthaw recovery for all DMSO concentrations, especially at higher DMSO concentration (5-10 wt \%). In fact, $10 \mathrm{wt} \%$ DMSO increased the recovery rate from $25 \%$ to $60 \%$ upon addition of AFPIII. Extracellular AFPIII combined with 5 wt \% DMSO also demonstrated a large increase in cell recovery (1.6fold), compared to the equivalent DMSO alone cell recoveries, and demonstrated the highest statistically significant increase compared to all other combination of treatments. In addition, extracellular AFPIII at 5 wt \% DMSO also obtained cell recoveries (38\%) greater than 10 wt \% DMSO alone, demonstrating that external AFPIII (in solution) could be used to reduce the total DMSO concentration required (which is biomedically important) while enhancing post-thaw cell recovery. Acker et al. demonstrated that, although intracellular ice formation is regarded as an inherently lethal event, innocuous intracellular ice exists and may even increase postthaw cell viability of multiple cell lines using slow freezing. ${ }^{65,66}$ Therefore, it is possible that extracellular ice growth recrystallization is the dominant cause of cell death and IRI active compounds are hence more potent when extracellular. Alternatively, nonspecific uptake of AFPIII could inhibit intracellular ice recrystallization sufficiently to avoid crystal sizes which have been deemed harmful in previous studies. ${ }^{67}$ AFPs are known to stabilize fatty acids located throughout the membrane during freezing and can cause membrane leakage, however this is highly dependent on lipid composition of the bilayer and thus individual cell types. ${ }^{68-70}$ Membrane leakage would allow the efflux of water, and most likely exchange with DMSO, to occur rapidly and prevent extensive intracellular ice growth. Regardless of the exact mechanism, these results confirm that, at least when DMSO is used on cell monolayers, that extracellular localization of antifreeze proteins provide significant benefit to monolayer cryopreservation of cells which, according to previous literature, is likely correlated to their ice recrystallization inhibition activity or membrane interactions. These effects were clearly less important for suspension cell cryopreservation suggesting that the primary mechanism of cell death are different in the two systems, and the cryoprotectants required will vary depending on the complexity of the cellular system being cryopreserved.

\section{CONCLUSIONS}

Here we present a study into the role of intra- versus extracellular antifreeze proteins, on the cryopreservation of a model cell line, showing how this localization has a dramatic effect on post-thaw cell recovery. The Pep-1 cell-penetrating peptide was employed to deliver recombinantly expressed type III antifreeze protein into A549 cells. Intracellular delivery was confirmed using confocal microscopy and flow cytometry, showing 5 times more internalization of AFPIII. Using conventional suspension cell freezing methods, with DMSO as the cryoprotectant, the antifreeze protein demonstrated minimal impact on post-thaw cell recovery, whether it was intra- or extracellular. This suggests that the primary mode of cell death in this system was not due to unwanted ice recrystallization, and hence the antifreeze protein offered limited protection. The same delivery strategy was subsequently applied to 2 -D cell monolayers, a more challenging cell cryopreservation system where DMSO alone fails to enable significant cell recovery. Without the antifreeze protein, only $\sim 25 \%$ of monolayer-frozen cells were recovered post-thaw. Insignificant increases in post-thaw recovery was observed when the antifreeze protein was delivered into the cell; however, when applied extracellularly, the post-thaw recovery of cells rose from $25 \%$ to over $60 \%$, representing a remarkable increase. These results provide evidence that extracellular macromolecular cryoprotectants result in superior cryoprotective effects when supplemented to DMSO cryopreservation and provides evidence that antifreeze proteins, and potentially additional macromolecular cryoprotectants, do not need to be designed with cellular uptake as a criterion. This work also shows that the requirements to enhance cell monolayer recovery are distinct from suspension, so a "one size fits all" approach might not always be suitable. Finally, these results show that the mechanisms of cell death during cryopreservation vary between systems. In summary, this work provides new insight into the requirements of a macromolecular cryoprotectant and provides a step forward toward being able to rationally design new materials to enable new therapies and biotechnological tools.

\section{ASSOCIATED CONTENT}

\section{Supporting Information}

The Supporting Information is available free of charge on the ACS Publications website at DOI: 10.1021/acs.biomac.9b00951.

Experimental procedures and additional microscopy images (PDF)

\section{AUTHOR INFORMATION}

\section{Corresponding Author}

*E-mail: M.I.Gibson@warwick.ac.uk (M. I. Gibson).

ORCID ${ }^{\circ}$

Matthew I. Gibson: 0000-0002-8297-1278

Notes

The authors declare no competing financial interest.

The research data supporting this publication can be found at http://wrap.warwick.ac.uk.

\section{ACKNOWLEDGMENTS}

M.I.G. holds an ERC starting grant (CRYOMAT 638661) and PoC Grant (789182). R.T. thanks EPSRC for a Ph.D. studentship through the EPSRC Centre for Doctoral Training in Molecular Analytical Science, (EP/L015307/1RT). BBSRC is thanked for supporting M.H. by an FTMA fellowship (BB/ R506588/1) and for the UoW Advanced Biolmaging RTP, BBSRC ALERT14 Award BB/M01228X/1. T.L.B. thanks M. Menze for providing the Biocision CoolCell to enable controlled rate freezing.

\section{REFERENCES}

(1) Bender, E. Cell Based-Therapy: Cells on Trial. Nature 2016, 540 (7634), S106-S108. 
(2) Lewis, J. K.; Bischof, J. C.; Braslavsky, I.; Brockbank, K. G. M.; Fahy, G. M.; Fuller, B. J.; Rabin, Y.; Tocchio, A.; Woods, E. J.; Wowk, B. G.; Acker, J.; Giwa, S. Cryobiology The Grand Challenges of Organ Banking: Proceedings from the First Global Summit on Complex Tissue Cryopreservation. Cryobiology 2016, 72 (2), 169-182.

(3) Lovelock, J. E.; Bishop, M. W. H. Prevention of Freezing Damage to Living Cells by Dimethyl Sulfoxide. Nature 1959, 183 (4672), 1394-1395.

(4) Mazur, P. Cryobiology: The Freezing of Biological Systems. Science 1970, 168 (3934), 939-949.

(5) Jang, T. H.; Park, S. C.; Yang, J. H.; Kim, J. Y.; Seok, J. H.; Park, U. S.; Choi, C. W.; Lee, S. R.; Han, J. Cryopreservation and Its Clinical Applications. Integr. Med. Res. 2017, 6 (1), 12-18.

(6) Costa, L. A.; Ottoni, M. H. F.; Santos, M. G.; Meireles, A. B.; Almeida, V. G.; Pereira, W. F.; Avelar-Freitas, B. A.; Brito-Melo, G. E. A. Dimethyl Sulfoxide (DMSO) Decreases Cell Proliferation and TNF- $\alpha$, IFN- $\gamma$, and IL-2 Cytokines Production in Cultures of Peripheral Blood Lymphocytes. Molecules 2017, 22 (1789), 1-10.

(7) Chaytor, J. L.; Tokarew, J. M.; Wu, K.; Leclère, M.; Tam, R. Y.; Capicciotti, J.; Guolla, L.; von Moos, E.; Findlay, C. S.; Allan, D. S.; Ben, R. N. Inhibiting Ice Recrystallization and Optimization of Cell Viability after Cryopreservation. Glycobiology 2012, 22 (1), 123-133.

(8) Iwatani, M.; Ikegami, K.; Kremenska, Y.; Hattori, N.; Tanaka, S.; Yagi, S.; Shiota, K. Dimethyl Sulfoxide Has an Impact on Epigenetic Profile in Mouse Embryoid Body. Stem Cells 2006, 24 (11), 25492556.

(9) Kawai, K.; Li, Y. S.; Song, M. F.; Kasai, H. DNA Methylation by Dimethyl Sulfoxide and Methionine Sulfoxide Triggered by Hydroxyl Radical and Implications for Epigenetic Modifications. Bioorg. Med. Chem. Lett. 2010, 20 (1), 260-265.

(10) Thaler, R.; Spitzer, S.; Karlic, H.; Klaushofer, K.; Varga, F. DMSO Is a Strong Inducer of DNA Hydroxymethylation in PreOsteoblastic MC3T3-E1 Cells. Epigenetics 2012, 7 (6), 635-651.

(11) Boland, M. J.; Nazor, K. L.; Loring, J. F. Epigenetic Regulation of Pluripotency and Differentiation. Circ. Res. 2014, 115 (2), 311324.

(12) Huang, Y. T.; Yan, H.; Sun, Y.; Jollick, J. A.; Baird, H. Cryopreserved Cell Monolayers for Rapid Detection of Herpes Simplex Virus and Influenza Virus. J. Clin. Microbiol. 2002, 40 (11), 4301-4303.

(13) Bahari, L.; Bein, A.; Yashunsky, V.; Braslavsky, I. Directional Freezing for the Cryopreservation of Adherent Mammalian Cells on a Substrate. PLoS One 2018, 13 (2), No. e0192265.

(14) Pasch, J.; Schiefer, A.; Heschel, I.; Rau, G. Cryopreservation of Keratinocytes in a Monolayer. Cryobiology 1999, 39 (2), 158-168.

(15) Pless-petig, G.; Knoop, S.; Rauen, U. Serum- and Albumin-Free Cryopreservation of Endothelial Monolayers with a New Solution. Organogenesis 2018, 14 (2), 107-121.

(16) Acker, J. P.; Elliott, J. A. W.; McGann, L. E. Intercellular Ice Propagation: Experimental Evidence for Ice Growth through Membrane Pores. Biophys. J. 2001, 81 (3), 1389-1397.

(17) Graham, B.; Bailey, T. L.; Healey, J. R. J.; Marcellini, M.; Deville, S.; Gibson, M. I. Polyproline as a Minimal Antifreeze Protein Mimic That Enhances the Cryopreservation of Cell Monolayers. Angew. Chem., Int. Ed. 2017, 56 (50), 15941-15944.

(18) Martinetti, D.; Colarossi, C.; Buccheri, S.; Denti, G.; Memeo, L.; Vicari, L. Effect of Trehalose on Cryopreservation of Pure Peripheral Blood Stem Cells. Biomed. Rep. 2017, 6 (3), 314-318.

(19) Bianchi, V.; Lappi, M.; Bonu, M. A.; Borini, A. Oocyte Slow Freezing Using a $0.2-0.3 \mathrm{M}$ Sucrose Concentration Protocol: Is It Really the Time to Trash the Cryopreservation Machine? Fertil. Steril. 2012, 97 (5), 1101-1107.

(20) Kim, H. J.; Lee, J. H.; Hur, Y. B.; Lee, C. W.; Park, S.; Koo, B. Marine Antifreeze Proteins : Structure, Function, and Application to Cryopreservation as a Potential Cryoprotectant. Mar. Drugs 2017, 15 (2), 1-27.

(21) Robles, V.; Valcarce, D. G.; Riesco, M. F. The Use of Antifreeze Proteins in the Cryopreservation of Gametes and Embryos. Biomolecules 2019, 9 (5), 181.
(22) Biggs, C. I.; Bailey, T. L.; Ben Graham; Stubbs, C.; Fayter, A.; Gibson, M. I. Polymer Mimics of Biomacromolecular Antifreezes. Nat. Commun. 2017, 8 (1), 1546.

(23) Biggs, C. I.; Stubbs, C.; Graham, B.; Fayter, A. E. R.; Hasan, M.; Gibson, M. I. Mimicking the Ice Recrystallization Activity of Biological Antifreezes. When Is a New Polymer "Active"? Macromol. Biosci. 2019, 19 (7), 1900082.

(24) Gibson, M. I. Slowing the Growth of Ice with Synthetic Macromolecules: Beyond Antifreeze(glyco) Proteins. Polym. Chem. 2010, 1 (8), 1141-1152.

(25) Knight, C. A.; Wen, D.; Laursen, R. A. Nonequilibrium Antifreeze Peptides and the Recrystallization of Ice. Cryobiology 1995, 32 (1), 23-34.

(26) Tomczak, M. M.; Hincha, D. K.; Estrada, S. D.; Wolkers, W. F.; Crowe, L. M.; Feeney, R. E.; Tablin, F.; Crowe, J. H. A Mechanism for Stabilization of Membranes at Low Temperatures by an Antifreeze Protein. Biophys. J. 2002, 82, 874-881.

(27) Eickhoff, L.; Dreischmeier, K.; Zipori, A.; Sirotinskaya, V.; Adar, C.; Reicher, N.; Braslavsky, I.; Rudich, Y.; Koop, T. Contrasting Behavior of Antifreeze Proteins: Ice Growth Inhibitors and Ice Nucleation Promotors. J. Phys. Chem. Lett. 2019, 10 (5), 966-972.

(28) Davies, P. L. Ice-Binding Proteins: A Remarkable Diversity of Structures for Stopping and Starting Ice Growth. Trends Biochem. Sci. 2014, 39 (11), 548-555.

(29) Deller, R. C.; Vatish, M.; Mitchell, D. A.; Gibson, M. I. Glycerol-Free Cryopreservation of Red Blood Cells Enabled by IceRecrystallization-Inhibiting Polymers. ACS Biomater. Sci. Eng. 2015, 1 (9), 789-794.

(30) Deller, R. C.; Vatish, M.; Mitchell, D. A.; Gibson, M. I. Synthetic Polymers Enable Non-Vitreous Cellular Cryopreservation by Reducing Ice Crystal Growth during Thawing. Nat. Commun. 2014, 5, 3244.

(31) Geng, H.; Liu, X.; Shi, G.; Bai, G.; Ma, J.; Chen, J.; Wu, Z.; Song, Y.; Fang, H.; Wang, J. Graphene Oxide Restricts Growth and Recrystallization of Ice Crystals. Angew. Chem., Int. Ed. 2017, 56 (4), 997-1001.

(32) Briard, J. G.; Poisson, J. S.; Turner, T. R.; Capicciotti, C. J.; Acker, J. P.; Ben, R. N. Small Molecule Ice Recrystallization Inhibitors Mitigate Red Blood Cell Lysis during Freezing, Transient Warming and Thawing. Sci. Rep. 2016, 6, 23619.

(33) Carpenter, J. F.; Hansen, T. N. Antifreeze Protein Modulates Cell Survival during Cryopreservation: Mediation through Influence on Ice Crystal Growth. Proc. Natl. Acad. Sci. U. S. A. 1992, 89 (19), 8953-8957.

(34) Deller, R. C.; Pessin, J. E.; Vatish, M.; Mitchell, D. A.; Gibson, M. I. Enhanced Non-Vitreous Cryopreservation of Immortalized and Primary Cells by Ice-Growth Inhibiting Polymers. Biomater. Sci. 2016, 4 (7), 1079-1084.

(35) Capicciotti, C. J.; Poisson, J. S.; Boddy, C. N.; Ben, R. N. Modulation of Antifreeze Activity and the Effect upon Post-Thaw HepG2 Cell Viability after Cryopreservation. Cryobiology 2015, 70 (2), 79-89.

(36) Matsumura, K.; Bae, J. Y.; Kim, H. H.; Hyon, S. H. Effective Vitrification of Human Induced Pluripotent Stem Cells Using Carboxylated Poly-L-Lysine. Cryobiology 2011, 63 (2), 76-83.

(37) Tsuruta, T.; Ishimoto, Y.; Masuoka, T. Effects of Glycerol on Intracellular Ice Formation and Dehydration of Onion Epidermis. Ann. N. Y. Acad. Sci. 1998, 858, 217-226.

(38) Toner, M.; Cravalho, E. G.; Karel, M. Thermodynamics and Kinetics of Intracellular Ice Formation during Freezing of Biological Cells. J. Appl. Phys. 1990, 67 (3), 1582-1593.

(39) Berger, W. K.; Uhrík, B. Freeze-Induced Shrinkage of Individual Cells and Cell-to-Cell Propagation of Intracellular Ice in Cell Chains from Salivary Glands. Experientia 1996, 52 (9), 843-850.

(40) Acker, J. P.; Mcgann, L. E. Cell - Cell Contact Affects Membrane Integrity after Intracellular Freezing. Cryobiology 2000, 40 (1), 54-63. 
(41) Irimia, D.; Karlsson, J. O. M. Kinetics of Intracellular Ice Formation in One-Dimensional Arrays of Interacting Biological Cells. Biophys. J. 2005, 88 (1), 647-660.

(42) Armitage, W. J.; Juss, B. K. Freezing Monolayers of Cells without Gap Junctions. Cryobiology 2003, 46, 194-196.

(43) Higgins, A. Z.; Karlsson, J. O. M. Effects of Intercellular Junction Protein Expression on Intracellular Ice Formation in Mouse Insulinoma Cells. Biophys. J. 2013, 105 (9), 2006-2015.

(44) Irimia, D.; Karlsson, J. O. M. Kinetics and Mechanism of Intercellular Ice Propagation in a Micropatterned Tissue Construct. Biophys. J. 2002, 82 (4), 1858-1868.

(45) Mazur, P. Freezing of Living Cells: Mechanisms and Implications. Am. J. Physiol. Physiol. 1984, 247 (3), C125-C142.

(46) Tatsutani, K.; Rubinsky, B. A Method to Study Intracellular Ice Nucleation. J. Biomech. Eng. 1998, 120 (1), 27-31.

(47) Asghar, W.; El Assal, R.; Shafiee, H.; Anchan, R. M.; Demirci, U. Preserving Human Cells for Regenerative, Reproductive, and Transfusion Medicine. Biotechnol. J. 2014, 9 (7), 895-903.

(48) Bailey, T. L.; Stubbs, C.; Murray, K.; Tomás, R. M. F.; Otten, L.; Gibson, M. I. A Synthetically Scalable Poly(ampholyte) Which Dramatically Enhances Cellular Cryopreservation. Biomacromolecules 2019, 20 (8), 3104-3114.

(49) Matsumura, K.; Kawamoto, K.; Takeuchi, M.; Yoshimura, S.; Tanaka, D.; Hyon, S.-H. Cryopreservation of a Two-Dimensional Monolayer Using a Slow Vitrification Method with Polyampholyte to Inhibit Ice Crystal Formation. ACS Biomater. Sci. Eng. 2016, 2 (6), 1023-1029.

(50) Fu, A.; Tang, R.; Hardie, J.; Farkas, M. E.; Rotello, V. M. Promises and Pitfalls of Intracellular Delivery of Proteins. Bioconjugate Chem. 2014, 25 (9), 1602-1608.

(51) Wilkins, L. E.; Hasan, M.; Fayter, A. E. R.; Biggs, C.; Walker, M.; Gibson, M. I. Site-Specific Conjugation of Antifreeze Proteins onto Polymer-Stabilized Nanoparticles. Polym. Chem. 2019, 10, 2986-2990.

(52) Petrescu, A. D.; Vespa, A.; Huang, H.; Mcintosh, A. L.; Schroeder, F.; Kier, A. B. Fluorescent Sterols Monitor Cell Penetrating Peptide Pep-1 Mediated Uptake and Intracellular Targeting of Cargo Protein in Living Cells. Biochim. Biophys. Acta, Biomembr. 2009, 1788 (2), 425-441.

(53) Gros, E.; Deshayes, S.; Morris, M. C.; Aldrian-herrada, G.; Depollier, J.; Heitz, F.; Divita, G. A. Non-Covalent Peptide-Based Strategy for Protein and Peptide Nucleic Acid Transduction. Biochim. Biophys. Acta, Biomembr. 2006, 1758 (3), 384-393.

(54) Räägel, H.; Säälik, P.; Pooga, M. Peptide-Mediated Protein Delivery - Which Pathways Are Penetrable? Biochim. Biophys. Acta, Biomembr. 2010, 1798 (12), 2240-2248.

(55) Kurzawa, L.; Pellerano, M.; Morris, M. C. PEP and CADYMediated Delivery of Fluorescent Peptides and Proteins into Living Cells. Biochim. Biophys. Acta, Biomembr. 2010, 1798 (12), 22742285.

(56) Henriques, T.; Costa, J.; Castanho, M. A. R. B. Translocation of B-Galactosidase Mediated by the Cell-Penetrating Peptide Pep-1 into Lipid Vesicles and Human HeLa Cells Is Driven by Membrane Electrostatic. Biochemistry 2005, 44 (30), 10189-10198.

(57) Heng, B. C.; Ye, C. P.; Liu, H.; Toh, W. S.; Rufaihah, A. J.; Yang, Z.; Bay, B. H.; Ge, Z.; Ouyang, H. W.; Lee, E. H.; Cao, T. Loss of Viability during Freeze - Thaw of Intact and Adherent Human Embryonic Stem Cells with Conventional Slow-Cooling Protocols Is Predominantly due to Apoptosis rather than Cellular Necrosis. J. Biomed. Sci. 2006, 13 (3), 433-445.

(58) Rahman, A. T.; Arai, T.; Yamauchi, A.; Miura, A.; Kondo, H.; Ohyama, Y.; Tsuda, S. Ice Recrystallization Is Strongly Inhibited When Antifreeze Proteins Bind to Multiple Ice Planes. Sci. Rep. 2019, 9 (1), 2212.

(59) Matsumoto, S.; Matsusita, M.; Morita, T.; Kamachi, H.; Tsukiyama, S.; Furukawa, Y.; Koshida, S.; Tachibana, Y.; Nishimura, S. I.; Todo, S. Effects of Synthetic Antifreeze Glycoprotein Analogue on Islet Cell Survival and Function during Cryopreservation. Cryobiology 2006, 52 (1), 90-98.
(60) Vorontsov, D. A.; Sazaki, G.; Titaeva, E. K.; Kim, E. L.; Bayergiraldi, M.; Furukawa, Y. Growth of Ice Crystals in the Presence of Type III Antifreeze Protein. Cryst. Growth Des. 2018, 18 (4), 25632571.

(61) Ishiguro, H.; Rubinsky, B. Mechanical Interactions between Ice Crystals and Red Blood Cells during Directional Solidification. Cryobiology 1994, 31 (5), 483-500.

(62) Congdon, T.; Notman, R.; Gibson, M. I. Antifreeze (Glyco)protein Mimetic Behavior of Poly(vinyl Alcohol): Detailed Structure Ice Recrystallization Inhibition Activity Study. Biomacromolecules 2013, 14, 1578-1586.

(63) Knight, C. A.; Hallett, J.; DeVries, A. L. Solute Effects on Ice Recrystallization: An Assessment Technique. Cryobiology 1988, 25 (1), 55-60.

(64) Poisson, J. S.; Acker, J. P.; Briard, J. G.; Meyer, J. E.; Ben, R. N. Modulating Intracellular Ice Growth with Cell-Permeating SmallMolecule Ice Recrystallization Inhibitors. Langmuir 2019, 35 (23), $7452-7458$

(65) Acker, J. P.; Mcgann, L. E. Innocuous Intracellular Ice Improves Survival of Frozen Cells. Cell Transplant 2002, 11 (18), 563-571.

(66) Acker, J. P.; Mcgann, L. E. Protective Effect of Intracellular Ice during Freezing? Cryobiology 2003, 46 (2), 197-202.

(67) Wesley-smith, J.; Berjak, P.; Pammenter, N. W.; Walters, C. Intracellular Ice and Cell Survival in Cryo-Exposed Embryonic Axes of Recalcitrant Seeds of Acer Saccharinum: An Ultrastructural Study of Factors Affecting Cell and Ice Structures. Ann. Bot. 2014, 113 (4), 695-709.

(68) Hays, L. M.; Crowe, J. H.; Wolkers, W.; Rudenko, S. Factors Affecting Leakage of Trapped Solutes from Phospholipid Vesicles during Thermotropic Phase Transitions. Cryobiology 2001, 42 (2), $88-102$.

(69) Tomczak, M. M.; Hincha, D. K.; Estrada, S. D.; Feeney, R. E.; Crowe, J. H. Antifreeze Proteins Differentially Affect Model Membranes during Freezing. Biochim. Biophys. Acta, Biomembr. 2001, 1511 (2), 255-263.

(70) Wu, Y.; Fletcher, G. L. Efficacy of Antifreeze Protein Types in Protecting Liposome Membrane Integrity Depends on Phospholipid Class. Biochim. Biophys. Acta, Gen. Subj. 2000, 1524 (1), 11-16. 